DOI: https://doi.org/10.24127/ajpm.v9i4.3171

\title{
ANALISIS PEDAGOGICAL CONTENT KNOWLEDGE GURU MATEMATIKA SEKOLAH MENENGAH PERTAMA DITINJAU DARI SEGI GENDER
}

\author{
Khumaeroh Dwi Nur’aini' ${ }^{1}$, Sadrack Luden Pagiling², \\ ${ }^{1,2}$ Universitas Musamus, Merauke, Indonesia \\ *Corresponding author \\ E-mail: $\quad$ khumaeroh_fkip@unmus.ac.id ${ }^{1)}$ \\ pagiling_fkip@unmus.ac.id ${ }^{2)}$
}

Received 19 October 2020; Received in revised form 06 December 2020; Accepted 21 December 2020

\begin{abstract}
Abstrak
Tujuan penelitian ini adalah untuk mendeskripsikan pedagogical content knowledge (PCK) guru matematika SMP di kabupaten Merauke pada materi segiempat yang ditinjau dari segi gender. Jenis penelitian ini adalah deskriptif kualitatif. Subjek terdiri atas dua guru perempuan dan dua guru laki-laki. Teknik pengumpulan data yang digunakan dalam penelitian ini yaitu penyebaran kuesioner PCK dan wawancara. Teknik analisis data yang digunakan yaitu triangulasi teknik yang meliputi reduksi data, penyajian data, dan menarik kesimpulan atau verifikasi. Hasil penelitian ini menunjukkan pengetahuan konten guru perempuan lebih baik daripada guru laki-laki. Untuk pengetahuan pedagogik keempat guru menunjukkan penguasaan tentang kurikulum dan kemampuan siswanya dengan sangat baik. Namun terkait rencana pembelajaran masing-masing guru memiliki rencana yang berbeda, ada yang menyusun RPP berdasarkan anjuran Kemendikbud 2020 dan ada pula yang menyusun RPP berdasarkan Kurikulum 2013, namun inti pembelajarannya sama, menggunakan metode pembelajaran diskusi dan tanya jawab untuk mengeksplorasi pengetahuan dan menemukan penyelesaian. Untuk pelaksanaan pembelajaran baik guru laki-laki maupun guru perempuan sama-sama representasi berupa benda-benda di sekitar siswa dengan harapan siswa dapat lebih mudah memahami materi bangun segiempat. Untuk pengetahuan terkait teknik evaluasi pembelajaran, baik guru laki-laki maupun guru perempuan memiliki pengetahuan dalam penilaian proses dan hasil belajar yang baik dengan mempertimbangkan tingkat pemahaman dan kemampuan siswa.
\end{abstract}

Kata kunci: guru matematika; pedagogical content knowledge; segiempat

\begin{abstract}
The purpose of this paper is to describe the pedagogical content knowledge (PCK) of junior high school mathematics teachers in Merauke district on quadrilateral in terms of gender. This type of research is descriptive qualitative. Subjects consisted of one female teacher and one male teacher. Data collection techniques used in this study were distributing PCK questionnaires and interviews. The data analysis technique used is the triangulation technique which includes data reduction, data presentation, and drawing conclusions or verification. The results of this study indicate that female teachers' content knowledge is better than male teachers. For pedagogic knowledge, both female and male teachers demonstrated excellent mastery of the curriculum and the abilities of their students. However, regarding the learning plan, each teacher has a different plan, there are those who prepare lesson plans based on recommendations from the Ministry of Education and Culture 2020 and some are compiling lesson plans based on the 2013 Curriculum, but the core of learning is the same, using discussion and question and answer learning methods to explore knowledge and find solutions. For the implementation of learning, both male and female teachers are representations of objects around students with the hope that students can more easily understand the material of rectangular shapes. For knowledge related to learning evaluation techniques, both male and female teachers have good knowledge in assessing learning processes and outcomes by considering the level of understanding and ability of students
\end{abstract}

Keywords: mathematics teacher; pedagogical content knowledge; quadrilateral 
DOI: https://doi.org/10.24127/ajpm.v9i4.3171

\section{PENDAHULUAN}

Guru adalah komponen kunci dalam pembelajaran, apalagi dalam pembelajaran matematika yang memiliki peran yang krusial dalam memfasilitasi siswa berpikir. Seorang guru harus menguasai konten matematika yang diajarkan dan tahu cara mentransfer pelajaran sehingga siswa dapat memahaminya dengan mudah. Pengetahuan konten seorang guru sangat krusial karena dapat memengaruhi prestasi belajar siswa. Namun, pengetahuan konten yang memadai tidak cukup untuk membangun pemahaman siswa dengan baik tanpa persiapan yang baik sebelum mengajar (pedagogical knowledge) yang termasuk dalam kompetensi profesional guru (Subanji, 2012).

Pengetahuan tentang pedagogi terkait dengan perencanaan dan pengorganisasian pembelajaran, representasi yang akan digunakan, pemilihan contoh dan tugas, metode perencanaan, dan teknik evaluasi (Ma'Rufi, Budayasa, \& Juniati, 2017). Sedangkan pengetahuan konten merupakan pengetahuan tentang materi yang diajarkan yang meliputi faktafakta, konsep, teori, dan prosedur. Dengan demikian, pedagocical content knowledge (PCK) merupakan kombinasi atau persenyawaan pengetahuan konten dengan pengetahuan pedagogis (Erwin \& Rustaman, 2017). Sejalan dengan pendapat tersebut, (Ekawati, Lin, \& Yang, 2015; Kersting, Givvin, Thompson, Santagata, \& Stigler, 2012) mengungkapkan bahwa PCK merupakan pengetahuan tentang mengajarkan konsep (termasuk memberi umpan balik), pengetahuan tentang siswa, pemahaman tentang konsep; pengetahuan tentang level tugas dan pengetahuan tentang pengajaran yang sesuai pendekatan untuk pemahaman siswa.

Penelitian yang menguraikan komponen pengetahuan pedagogi dilakukan oleh (Lestari, Juniati, \& Suwarsono, 2018); dan (Muhtarom, Juniati, \& Siswono, 2019).

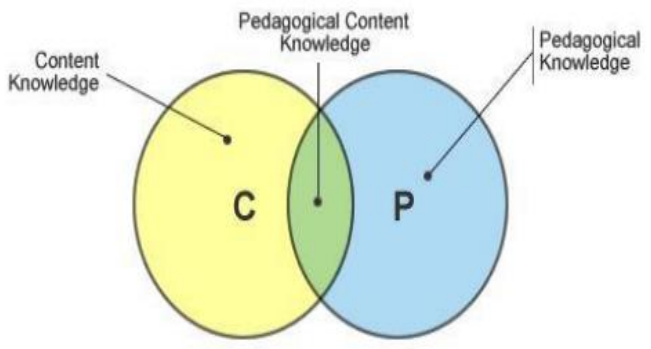

Gambar 1. Component of Pedagogical Content Knowledge (Rochintaniawati, Widodo, Riandi, \& Herlina, 2018)

Beberapa penelitian telah mendokumentasikan tentang pedagogical content knowledge (PCK) guru matematika (Copur-Gencturk, 2015; Kersting et al., 2012; Kleickmann et al., 2015; Ma'Rufi et al., 2017). Hasil penelitian (Copur-Gencturk, 2015) menunjukkan bahwa peningkatan pengetahuan matematika guru dapat meningkatkan kualitas desain pembelajaran, agenda matematika dan iklim pembelajaran di kelas. Kleikmann dan kolega (Kleickmann et al., 2015) yang menginvestigasi guru di Taiwan dan Jerman menekankan bahwa pengetahuan konten matematika sangat berkaitan dengan PCK seorang guru yang berimplikasi pada pengembangan profesionalisme. Hasil penelitian (Ma'Rufi et al., 2017) menjelaskan bahwa guru pemula cenderung memiliki pengetahuan pedagogi yaitu kurang variasi dalam penggunaan strategi pembelajaran, mengajukan pertanyaan yang monoton, tidak memanfaatkan potensi siswa, tidak 
memberikan ilustrasi, dan menjelaskan secara prosedural.

Penelitian tentang PCK masih perlu dilakukan. Melalui pengetahuan seorang guru terhadap konten dan metode pengajaran yang baik akan membantu siswa lebih mudah membangun pemahaman, terutama bagi guru matematika yang harus mampu memberikan siswa pemahaman terhadap konsep yang abstrak agar dapat diserap dengan mudah. Khususnya pada materi geometri yang berkaitan erat dengan pembentukan konsep abstrak. Pembelajaran ini tidak bisa hanya dilakukan dengan transfer pengetahuan atau ceramah saja, tetapi harus dilakukan dengan pembentukan konsep melalui rangkaian kegiatan yang dilakukan langsung oleh siswa (Nurhasanah, Kusumah, \& Sabandar, 2017). Lim dan Guera meneliti 29 guru dan menyimpulkan bahwa pengetahuan konten guru secara keseluruhan tidak kuat dan dua bidang pengetahuan konten kinerjanya paling rendah adalah Geometri (Lim \& Guerra, 2013).

Selain PCK, faktor lain yang dapat memengaruhi hasil belajar siswa adalah pengaruh gender guru. Gender dalam penelitian ini terfokus pada jenis kelamin, yakni laki-laki dan perempuan. Perbedaan yang ada pada laki-laki dan perempuan, baik secara psikis maupun fisik akan mempengaruhi kepribadian seseorang yang mencakup daya tarik fisik, perasaan, kedewasaan serta pola pikir atas objek yang diamatinya (Auhadeeva, Yarmakeev, \& Aukhadeev, 2015). Stereotip masyarakat terkait gender, umumnya cenderung menganggap laki-laki lebih kompeten dan lebih berprestasi daripada perempuan dalam bidang tertentu seperti bidang ilmu yang berhubungan dengan kemampuan matematika dan ilmu teknik (Qiao-Ping, Ngai-Ying, \&
Chi-Chung, 2013). Lebih lanjut, guru laki-laki dalam menghadapi muridnya lebih banyak mengajar berdasarkan pengalamannya saat masih belajar, sedangkan guru perempuan lebih banyak mengajar dengan menggunakan sistem pengajaran yang sesuai dengan ketetapan pendidikan yang berlaku, selain itu guru perempuan akan lebih peka terhadap kondisi siswa dibanding guru laki-laki.

Menurut (Subanji, 2012) tingkah laku guru dipengaruhi oleh pengetahuan guru tentang topik tertentu dan pengetahuan tentang bagaimana cara siswa dalam mempelajari topik tersebut. Sehingga kemampuan mengajar guru akan dipengaruhi oleh gender guru yang berkaitan dengan PCK guru tentang topik tertentu. Penelitian (Ma'Rufi, Ikram, \& Ilyas, 2020) menunjukkan bahwa calon guru laki-laki mengajarkan materi trigonometri dengan menggunakan strategi ekspositori dan penggunaan berbagai bentuk representasi seperti gambar untuk memfasilitasi pemahaman peserta didik tetapi masih mengandalkan powerpoint sebagai media utama sehingga aktivitas belajar siswa belum maksimal. Sedangkan calon guru perempuan yang memiliki kemampuan tinggi menerapkan pembelajaran kooperatif dengan metode penemuan terbimbing untuk mengajarkan konsep, namun pelaksanaan pembelajaran belum berfokus ke siswa sehingga tujuan pembelajaran kooperatif belum tercapai.

Seperti yang telah dipaparkan sebelumnya, penelitian terkait PCK Guru telah cukup banyak dilakukan oleh Ma'Rufi et al., (2017); Ma'Rufi, Budayasa, \& Juniati (2018); Ma'Rufi et al., (2020); Muhtarom et al., (2019), namun penelitian-penelitian tersebut baru membahas mengenai PCK Guru dan Calon Guru secara umum. 
Kemudian penelitian pada segiempat cenderung berfokus pada pemecahan masalah dan kesulitan siswa dalam menyelesaikan masalah segiempat (Fujita, 2012; Fujita, Doney, \& Wegerif, 2019). Sehingga penelitian tentang PCK guru dalam mengajarkan segiempat yang ditinjau dari segi gender perlu dilakukan guna mendapatkan gambaran lebih rinci terkait PCK guru matematika.

Tujuan penelitian ini adalah untuk mendeskripsikan pedagogical content knowledge (PCK) guru matematika SMP di kabupaten Merauke pada materi segiempat yang ditinjau dari segi gender sehingga guru bisa merefleksikan pembelajaran pada materi segiempat dan melakukan penilaian diri sendiri (self-assesment).

\section{METODE PENELITIAN}

Penelitian ini merupakan penelitian deskriptif dengan pendekatan kualitatif yang merupakan metode yang berusaha menggambarkan dan menginterpretasikan objek sesuai dengan apa adanya. Peneliti ikut berpartisipasi selama di lapangan mencatat secara hati-hati apa yang terjadi, melakukan analisis reflektif terhadap berbagai dokumen yang ditemukan di lapangan dan membuat laporan penelitian secara detail. Subjek Penelitian terdiri atas empat orang guru matematika di SMP yang berbeda. Kriteria pemilihan subjek penelitian adalah: 1) Berbeda gender, yakni guru laki-laki dan guru perempuan. 2) Berasal dari sekolah yang berbeda. 3) Memiliki pengalaman mengajar yang sama, yakni 11 Tahun. 4) Bersedia untuk berpartisipasi dalam penelitian. Subjek guru laki-laki diberi simbol SL01 dan SL02, subjek guru perempuan diberi simbol SP01 dan SP02. Pengumpulan data dilakukan dengan menyebarkan kuesioner PCK dan wawancara secara mendalam terkait materi segiempat terhadap subjek penelitian. Indikator yang digunakan dalam penelitian ini diadaptasi dari indikator yang digunakan oleh (Ma'Rufi et al., 2017). Selanjutnya untuk menguji kredibilitas data, peneliti menggunakan triangulasi teknik.

\section{HASIL DAN PEMBAHASAN}

Temuan dari penelitian ini adalah eksplorasi yang mendalam mengenai komponen PCK Guru Matematika yang terungkap melalui angket dan wawancara terkait pembelajaran matematika pada topik Segiempat di Sekolah Menengah Pertama.

\section{Pengetahuan Konten (Content Knowledge)}

Pengetahuan konten meliputi pengetahuan guru matematika SMP terkait materi segiempat yang ditinjau dari segi gender. Berdasarkan hasil angket dan wawancara, diperoleh hasil bahwa untuk pengetahuan konten terkait pemahaman tentang materi segiempat, Subjek SL01, SP01 dan SP02 menunjukkan penguaasaan materi segiempat yang sangat baik. Terbukti dari SL01 dan SP02 mampu menjawab 6 dari 7 pertanyaan sedangkan SP01 mampu menjawab seluruh pertanyaan terkait materi segiempat yang diajukan oleh peneliti. Hal ini mengindikasikan bahwa ketiga subjek tersebut sudah memahami definisi bangun segiempat serta hubungan antara bangun segiempat dengan sangat baik. Sedangkan untuk Subjek SL02 mampu mampu menjawab 3 dari 7 pertanyaan terkait materi segiempat yang diajukan oleh peneltiti. Hal ini mengindikasikan bahwa subjek cukup memahami definisi bangun segiempat namun belum cukup 
DOI: https://doi.org/10.24127/ajpm.v9i4.3171

memahami hubungan-hubungan yang ada antar bangun-bangun segiempat.

\section{Pengetahuan Pedagogi (Pedagogical} Knowledge)

Pengetahuan Pedagogik guru matematika meliputi Pengetahuan tersebut terdiri atas pengetahuan akan strategi pembelajaran pada materi segiempat yang mencakup pengetahuan tentang metode, aktivitas pemahaman, konsepsi, dan miskonsepsi siswa pada materi segiempat termasuk cara guru untuk mengatasi miskonsepsi tersebut. Selain itu juga meliputi Pengetahuan tentang kurikulum dan standar yang meliputi pengetahuan guru tentang tujuan kurikulum, tujuan pembelajaran, program, dan materi yang relevan ke pembelajaran materi segiempat hingga teknik penilaian yang dilakukan. Secara rinci, akan dibahas untuk masingmasing indikator dalam Pedagogical Knowledge (Tabel 1).

Tabel 1. Pengetahuan pedagogik (pedagogical knowledge) pada indikator penyusunan rencana pelaksanaan pembelajaran guru matematika berdasarkan gender.

\begin{tabular}{|c|c|c|c|}
\hline \multicolumn{2}{|c|}{ Subjek Laki-laki } & \multicolumn{2}{|c|}{ Subjek Perempuan } \\
\hline SL01 & SL02 & SP01 & SP02 \\
\hline $\begin{array}{l}\text { Subjek menyusun } \\
\text { RPP berdasarkan } \\
\text { arahan } \\
\text { Kemendikbud } 2020 \\
\text { tentang RPP } 1 \\
\text { Lembar yang berisi } \\
\text { Tujuan } \\
\text { Pembelajaran, } \\
\text { Langkah-langkah } \\
\text { pembelajaran } \\
\text { (Metode) dan } \\
\text { Evaluasi/Penilaian } \\
\text { dengan perangan } \\
\text { mempertimbangkan } \\
\text { aspek pemahaman } \\
\text { siswa dalam proses } \\
\text { pembelajaran } \\
\text { dalam pan } \\
\text { penyusunannya. } \\
\text { Untuk Media } \\
\text { Pembelajaran, } \\
\text { Subjek mek } \\
\text { menggunakan } \\
\text { benda-benda } \\
\text { disekitar untuk } \\
\text { memberikan contoh } \\
\text { real bentuk-bentuk } \\
\text { segiempat. }\end{array}$ & 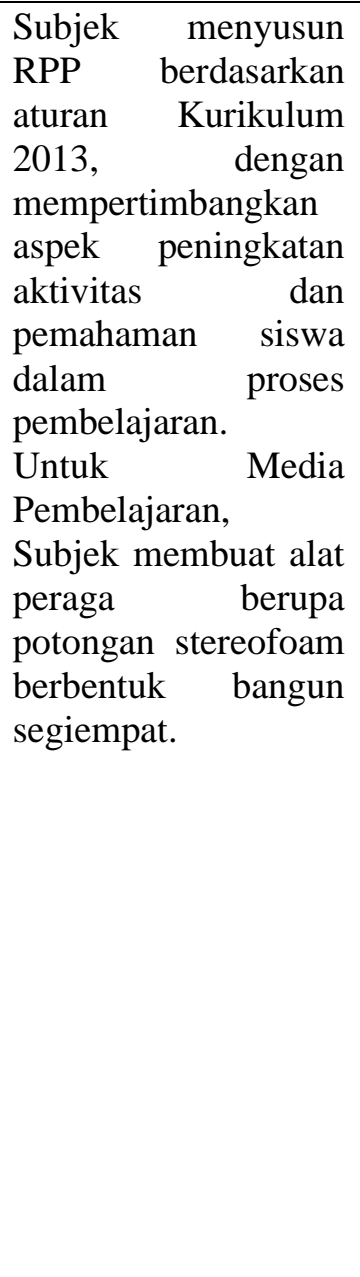 & $\begin{array}{lr}\text { Subjek } & \text { menyusun } \\
\text { RPP berdasarkan } \\
\text { aturan Kurikulum } \\
2013 \text {, dengan } \\
\text { mempertimbangkan } \\
\text { aspek kompetensi } \\
\text { dasar dalam silabus } \\
\text { dan tujuan } \\
\text { pembelajaran. } \\
\text { Untuk Media } \\
\text { Pembelajaran, } \\
\text { Subjek membuat } \\
\text { alat peraga berupa } \\
\text { potongan karton } \\
\text { atau kertas. }\end{array}$ & 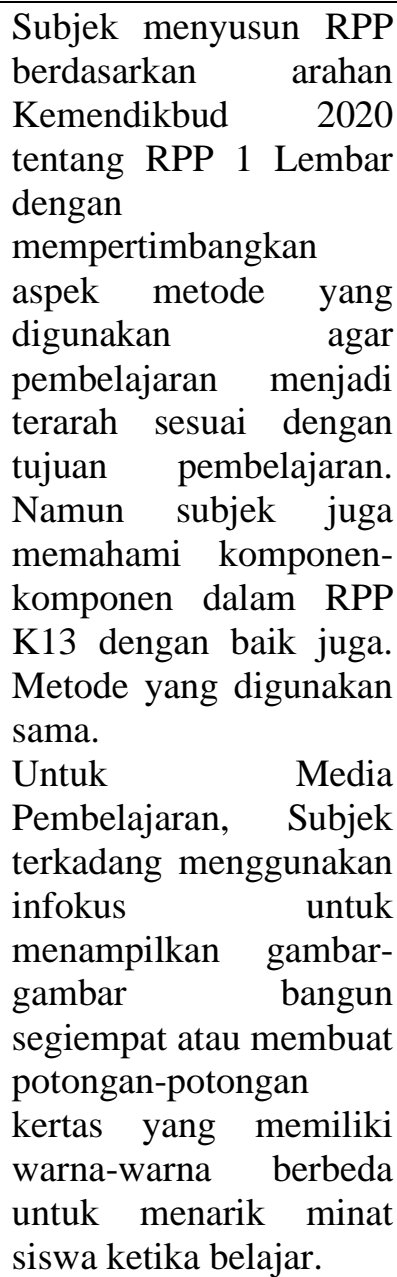 \\
\hline
\end{tabular}


DOI: https://doi.org/10.24127/ajpm.v9i4.3171

\section{Indikator Penyusunan Rencana Pelaksanaan Pembelajaran}

Ke-empat Subjek menunjukkan pengetahuan terkait penyusunan rencana pelaksanaan pembelajaran dengan sangat baik. Keempat Subjek sepakat bahwa dalam pembelajaran subjek tidak hanya berperan sebagai penyedia informasi mengenai aturan dan prosedur, tetapi juga membantu siswa bagaimana membangun pemahaman. sehingga metode pembelajaran yang biasa (sebelum covid-19) digunakan oleh keempat subjek adalah sama, yakni pembagian kelompok, diskusi dan tanya jawab. Menurut semua Subjek, dengan berdiskusi, siswa akan lebih mudah memahami materi jika bisa berdiskusi dengan teman-temannya, siswa saling berinteraksi dan berbagi informasi dengan bahasa dan gaya mereka masing-masing. Namun, Keempat Subjek tidak melakukan perubahan urutan materi dan mengajar sesuai urutan yang ada didalam buku teks dan silabus saja. Semua subjek mampu menyebutkan materi prasyarat yang harus dimiliki siswa untuk mempelajari materi segiempat, seperti Garis, Kedudukan garis, Sudut dan bentuk bangun datar yang sudah dipelajari di Sekolah Dasar. Terkait Penyusunan RPP, dapat dilihat pada Tabel 1.

\section{Indikator Memilih Representasi}

Keempat subjek sama-sama menggunakan representasi (benda/ide) berupa alat peraga dan contoh bangunbangun segiempat yang ada disekitar kelas, seperti bentuk meja, papan tulis, ubin lantai, pintu, dan lain-lain dalam pemebelajaran segiempat. Bagi subjek, represenatasi sangatlah penting untuk memperkuat pemahaman siswa tentang materi segiempat. Menurut subjek, dengan menggunakan representasi tersebut siswa menjadi lebih mudah memahami materi karena siswa dapat melihat dan menemukan secara langsung benda-benda yang menyerupai bentuk bangun-bangun segiempat.

\section{Indikator Memilih Tugas Matematika}

Bagi Keempat subjek, memberikan contoh soal dalam pembelajaran merupakan suatu rutinitas yang dilakukan dalam pembelajaran matematika. menurutnya dengan memberikan contoh soal, dapat melatih serta melihat bagaimana peningkatan pemahaman siswa pada proses pembelajaran.

Subjek selalu menyelipkan soal-soal non-rutin dalam pembelajaran guna melatih keterampilan pemecahan masalah siswa, namun hanya sebagian kecil siswa yang memiliki kemampuan akademik diatas rata-rata yang mampu menyelesaikan masalah-masalah tersebut, sementara siswa lainnya harus diberikan pendampingan dan waktu lebih untuk dapat menyelesaikannya.

\section{Indikator Pengajuan Pertanyaan dan Miskonsepsi Siswa}

Semua subjek selalu melakukan konfirmasi atas jawaban-jawaban siswanya. Subjek mampu memandu siswa dalam menemukan jawaban, selain itu subjek juga mendorong siswa untuk mengkonstruk pengetahuan. Bahkan subjek juga mampu memberikan alternatif pembelajaran untuk mengurangi kesalahan yang dilakukan siswa, baik konsep maupun prosedur.

\section{Indikator Teknik Penilaian/ Evaluasi}

Ketika siswa kesulitan menjawab pertanyaan, Keempat subjek memberikan jawaban yang sama, yakni akan memberikan pendampingan (Scaffolding) berupa pertanyaanpertanyaan yang dapat membantu siswa mengingat kembali konsep dasar materi 
DOI: https://doi.org/10.24127/ajpm.v9i4.3171

sehingga siswa bisa mengaitkan dengan masalah yang sedang dikerjakan. Terkait Pemahaman guru terhadap konsepsi dan miskonsepsi yang sering

Tabel 2. Pengetahuan pedagogik (pedagogical knowledge) pada indikator pengajuan pertanyaan dan miskonsepsi siswa guru matematika berdasarkan gender.

\begin{tabular}{|c|c|c|c|}
\hline \multicolumn{2}{|c|}{ Subjek Laki-laki } & \multicolumn{2}{|c|}{ Subjek Perempuan } \\
\hline SL01 & SL02 & SP01 & SP02 \\
\hline 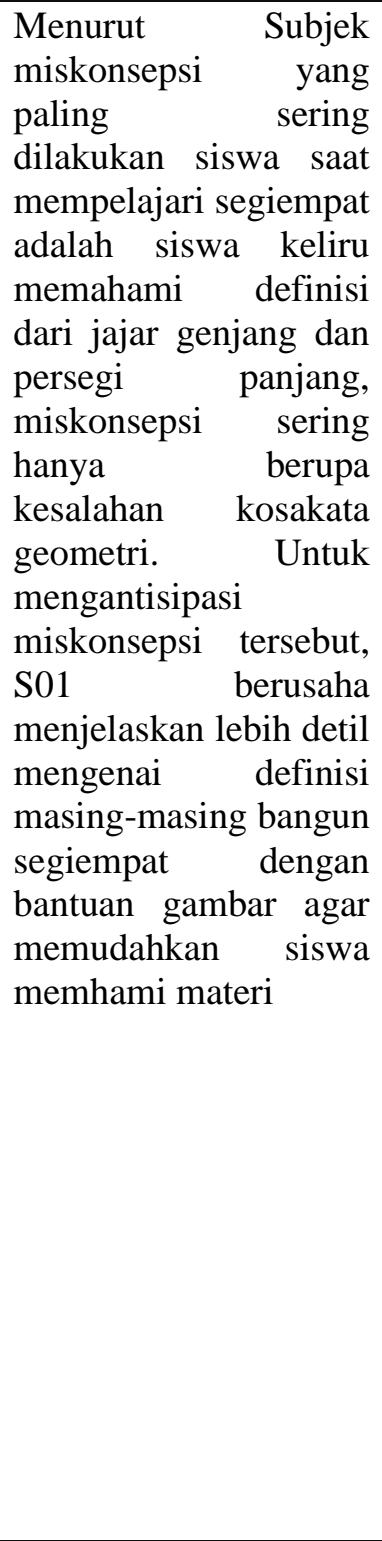 & $\begin{array}{l}\text { Menurut subjek, } \\
\text { miskonsepsi yang } \\
\text { sering terjadi } \\
\text { adalah keliru dalam } \\
\text { menggunakan } \\
\text { rumus Luas layang- } \\
\text { layang dan belah } \\
\text { ketupat, untuk } \\
\text { konsep definisi } \\
\text { bangun segiempat, } \\
\text { siswa juga keliru } \\
\text { pada definisi dan } \\
\text { gambar layang- } \\
\text { layang dan belah } \\
\text { ketupat. Untuk } \\
\text { mengatasi } \\
\text { miskonsepsi } \\
\text { tersebut, biasanya } \\
\text { subjek langsung } \\
\text { mengarahkan siswa } \\
\text { untuk } \\
\text { mengingat/memba } \\
\text { wa layang-layang } \\
\text { ketika } \\
\text { pembelajaran } \\
\text { berlangsung. }\end{array}$ & 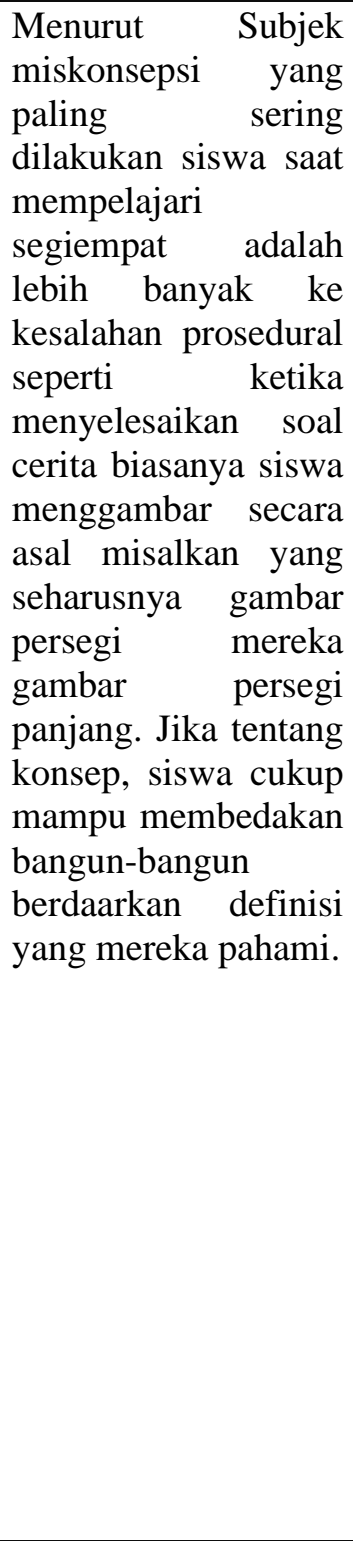 & 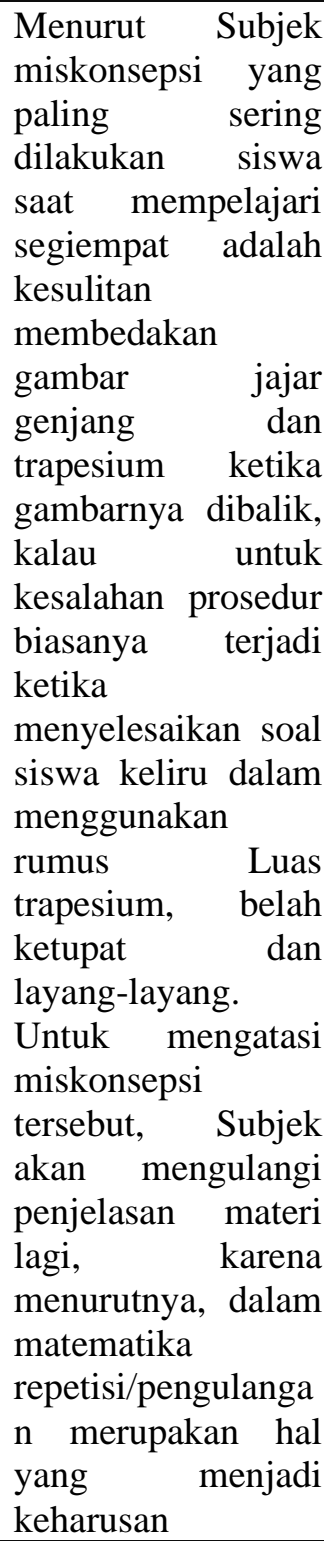 \\
\hline
\end{tabular}


DOI: https://doi.org/10.24127/ajpm.v9i4.3171

\section{Indikator Perbaikan Pembelajaran}

Subjek SL01 dan S02 menyarankan hal sama terkait perbaikan pembelajaran materi segiempat yakni Subjek menyarankan agar pembelajaran segiempat lebih banyak menggunakan alat peraga dan metode demonstrasi/praktek agar siswa bisa memiliki pengalaman langsung terkait materi segiempat. Sedangkan Subjek SP01 dan SP02 memberikan saran agar pembelajaran segiempat lebih mengutamakan pemahaman siswa terhadap definisi masing-masing bangun segiempat, dengan begitu siswa akan tetap mengetahui jenis bagun segiempat walaupun bentuknya diubah/dibalik gambarnya sehingga dengan sendirinya siswa bisa mengaitkan definisi dan rumus-rumus masing-masing bangun segiempat.

Berdasarkan hasil penelitian diperoleh bahwa pengetahuan konten guru perempuan tentang materi konsep segiempat lebih baik dari guru laki-laki. Hal ini terlihat dari guru perempuan dapat menjawab hampir seluruh soal yang diajukan oleh peneliti mengenai konsep-konsep bangun segiempat dengan sangat baik, sedangkan salah satu guru laki-laki mampu menjawab sebagian besar pertanyaan dengan 1 jawaban keliru terkait konsep jajar genjang dan trapesium dan satu guru laki-laki hanya mampu menjawab 3 dari 7 pertanyaan yang diajukan peneliti. Hal ini mematahkan stereotip yang menyatakan bahwa laki-laki lebih kompeten dan lebih berprestasi daripada perempuan dalam bidang tertentu seperti bidang ilmu yang berhubungan dengan kemampuan matematika dan ilmu teknik, seperti pada hasil penelitian yang dilakukan oleh Tiedelman (QiaoPing et al., 2013).

Keempat subjek menunjukkan penguasaan pengetahuan pedagogik yang sangat baik. Subjek menguasai pengetahuan akan strategi pembelajaran pada materi segiempat yang mencakup pengetahuan tentang metode, aktivitas pemahaman, konsepsi, dan miskonsepsi siswa pada materi segiempat termasuk cara guru untuk mengatasi miskonsepsi tersebut. Guru laki-laki maupun Guru Perempuan juga menyadari pentingnya perencanaan dan media pembelajaran untuk memfasilitasi siswa belajar di kelas. Hal tersebut sejalan dengan penelitian (Lestari et al., 2018), dan yang menjelaskan bahwa pengetahuan pedagogi berkaitan dengan kemampuan perencanaan pembelajaran dan manajemen kelas untuk memfasilitasi siswa belajar matematika. Selain itu semua Subjek juga memiliki pengetahuan tentang kurikulum dan standar yang meliputi pengetahuan guru tentang tujuan kurikulum, tujuan pembelajaran, program, dan materi yang relevan ke pembelajaran materi segiempat hingga teknik penilaian yang dilakukan.

Keempat subjek mengetahui materi prasyarat yang harus dikuasai dan tujuan pembelajaran yang berdampak pada pengambilan keputusan dalam pemilihan metode, dan media pembelajaran. Menurut Gilbert dkk (Biber, Tuna, \& Korkmaz, 2013) siswa belajar materi baru dengan mengombinasikan pengetahuan baru dengan pengalaman dan pengetahuan yang sudah ada. Akibatnya, guru perlu mempertimbangkan pengetahuan sebelumnya termasuk miskonsepsimiskonsepsi yang mungkin ada pada materi sebelumnya. Pembelajaran dimulai dengan memberikan masalah kepada siswa; membimbing siswa, berdiskusi untuk mengeksplorasi pengetahuan dan menemukan penyelesaian (Felbrich, Kaiser, \& Schmotz, 2012; Muhtarom et al., 2019). 
Ke-empat subjek memiliki pendapat yang sama dalam memilih menggunakan representasi berupa benda-benda di sekitar siswa dengan harapan siswa dapat lebih mudah memahami materi bangun segiempat jika melihat contoh bendanya secara langsung. Hal tersebut sesuai dengan penelitian (Muhtarom et al., 2019) yang menyarankan agar guru sebaiknya menggunakan peraga konkret sebelum pengajaran simbolik formal karena alat peraga berperan penting dalam konstruksi ide-ide bermakna siswa.

Baik guru perempuan maupun guru laki-laki, pernah memberikan soal non-rutin dengan tujuan untuk menambah pemahaman dan keterampilan siswa dalam menyelesaikan soal. Hal ini sejalan dengan pendapat (Ma'Rufi et al., 2017) bahwa guru harus dapat menyajikan konten dengan berbagai cara seperti; masalah masalah kontekstual atau gambar. Selain itu, penelitian ini mendukung penelitian Muhtarom yaitu guru perlu memiliki pengetahuan untuk mengatur konten matematika, menggunakan contoh untuk memulai atau contoh untuk memperdalam pemahaman siswa (Muhtarom et al., 2019).

Selanjutnya, Semua subjek telah memfasilitasi dan memandu siswa daripada menyediakan jawaban dan penjelasan, menilai pemahaman siswa, menghargai dan mendorong siswa untuk mengonstruksi pengetahuan. Subjek tahu waktu yang tepat untuk bertanya, kapan harus menggunakan jawaban siswa untuk menghasilkan ide matematika, dan kapan harus mengajukan pertanyaan baru atau untuk memberikan tugas baru untuk melanjutkan pembelajaran. (Karahasan, 2010) menjelaskan bahwa peran guru adalah mendiagnosis kesalahan siswa dan menunjukkan kesulitan siswa, memandu dan memfasilitasi siswa daripada menyediakan jawaban, penjelasan, dan menyadari kebutuhan siswa. Keempat subjek memiliki pengetahuan yang baik dalam penilaian proses dan hasil belajar. Muhtarom et al., (2019) menjelaskan bahwa guru perlu memahami dan mengambil tindakan yang tepat untuk mengatasi kesulitan belajar dan kesalahan siswa melalui berbagai teknik evaluasi yang tepat.

\section{KESIMPULAN DAN SARAN}

Berdasarkan hasil penelitian dapat disimpulkan bahwa pengetahuan konten guru perempuan tentang konsep segiempat lebih baik dari guru laki-laki. Selanjutnya, untuk pengetahuan pedagogik keempat guru menunjukkan penguasaan tentang kurikulum dan kemampuan siswanya dengan sangat baik. Namun terkait rencana pembelajaran masing-masing guru memiliki rencana yang berbeda, ada yang menyusun RPP berdasarkan anjuran Kemendikbud 2020 dan ada pula yang menyusun RPP berdasarkan Kurikulum 2013, namun inti pembelajarannya sama, menggunakan metode pembelajaran diskusi dan tanya jawab untuk mengeksplorasi pengetahuan dan menemukan penyelesaian.

Pelaksanaan pembelajaran keempat guru sama-sama menggunakan representasi berupa benda-benda di sekitar siswa dengan harapan siswa dapat lebih mudah memahami materi bangun segiempat. Untuk pengetahuan terkait teknik evaluasi pembelajaran, keempat guru memiliki pengetahuan dalam penilaian proses dan hasil belajar yang baik dengan mempertimbangkan tingkat pemahaman dan kemampuan siswa. Namun agar pembelajaran lebih baik, disarankan agar guru melakukan 
perubahan urutan materi segiempat agar lebih memudahkan siswa dalam memelajarinya. Seperti pendapat (Stevenson, 2020; Subanji, 2012) guru sebaiknya merancang pembelajaran sedemikian rupa sehingga mengurangi beban kognitif eksentrik siswa yang akhirnya siswa tidak perlu lagi menghafalkan satu per satu definisi dan sifat-sifat setiap bangun segiempat seperti yang selama ini terjadi.

Untuk penelitian selanjutnya, disarankan agar menambahkan teknik pengumpulan data melalui video pembelajaran guru terkait materi segiempat agar dapat melihat kesesuaian antara hasil wawancara dengan realita mengajar di kelas. Seperti yang dikemukakan oleh Simon dan Tzur (Maryono, 2015) bahwa praktik guru sebagai kesatuan yang tidak bisa dipahami dengan hanya melihat bagian dari keseluruhan, yaitu hanya melihat keyakinan, pertanyaan, atau pengetahuan matematika, dan lain-lain. Sehingga seorang guru yang mempunyai pengetahuan yang baik, sudah seharusnya mampu mempraktikkan pengetahuannya juga dengan baik.

\section{UCAPAN TERIMAKASIH}

Terimakasih kepada Direktorat Riset dan Pengabdian Masyarakat. Deputi Bidang Penguatan Riset dan Pengembangan Kementerian Riset dan Teknologi/ Badan Riset dan Inovasi Nasional Nomor DIPA: SP DIPA042.06.1.401516/2020, tanggal 12 November 2019 yang telah mendanai penelitian ini dengan kontrak Penelitian Dosen Pemula Tahun Anggaran 2020 Nomor:119.9/UN52.8/LT/2020. Terima kasih juga kepada Universitas Musamus, Khususnya LPPM Universitas Musamus yang telah memfasilitasi penelitian ini.

\section{DAFTAR PUSTAKA}

Auhadeeva, L. A., Yarmakeev, I. E., \& Aukhadeev, A. E. (2015). Gender competence of the modern teacher. International Education Studies, 8(2), 32-37. https://doi.org/10.5539/ies.v8n2p3 2

Biber, Ç., Tuna, A., \& Korkmaz, S. (2013). The Mistakes and the Misconceptions of the Eighth Grade Students on the Subject of Angles., 1(2), 50-59.

Copur-Gencturk, Y. (2015). Factors that influence the Problem Solving Ability: A longitudinal study of teachers' knowledge and instruction. Journal for Research in Mathematics Education, 46(3), 280-330.

Ekawati, R., Lin, F. L., \& Yang, K. L. (2015). Primary teachers' knowledge for teaching ratio and proportion in mathematics: The case of Indonesia. Eurasia Journal of Mathematics, Science and Technology Education, 11(3), 513533.

https://doi.org/10.12973/eurasia.20 $15.1354 \mathrm{a}$

Erwin, E., \& Rustaman, N. Y. (2017). Understanding of Prospective Physics Teachers Students Toward Pedagogical Content Knowledge on Optical Geometry Materials. Journal of Physics: Conference Series, 895(1). https://doi.org/10.1088/17426596/895/1/012102

Felbrich, A., Kaiser, G., \& Schmotz, C. (2012). The cultural dimension of beliefs: an investigation of future primary teachers' epistemological beliefs concerning the nature of mathematics in 15 countries. ZDM - International Journal on Mathematics Education, 44(3), 
DOI: https://doi.org/10.24127/ajpm.v9i4.3171

355-366.

https://doi.org/10.1007/s11858-

012-0418-x

Fujita, T. (2012). Learners' level of understanding of the inclusion relations of quadrilaterals and prototype phenomenon. Journal of Mathematical Behavior, 31(1), 6072.

https://doi.org/10.1016/j.jmathb.20 11.08.003

Fujita, T., Doney, J., \& Wegerif, R. (2019). Students' collaborative decision-making processes in defining and classifying quadrilaterals: a semiotic/dialogic approach. Educational Studies in Mathematics, 101(3), 341-356. https://doi.org/10.1007/s10649019-09892-9

Karahasan, B. (2010). Pre-servis Secondary Mathematics Teachers' Pedagogical Content Knowledge of Composite and Inverse Functions. Middle East Technical University, Turki.

Kersting, N. B., Givvin, K. B., Thompson, B. J., Santagata, R., \& Stigler, J. W. (2012). Measuring Usable Knowledge: Teachers' Analyses of Mathematics Classroom Videos Predict Teaching Quality and Student Learning. American Educational Research Journal, 49(3), 568-589. https://doi.org/10.3102/000283121 2437853

Kleickmann, T., Richter, D., Kunter, M., Elsner, J., Besser, M., Krauss, S., ... Baumert, J. (2015). Content knowledge and pedagogical content knowledge in Taiwanese and German mathematics teachers. Teaching and Teacher Education, 46 , 115-126. https://doi.org/10.1016/j.tate.2014. 11.004
Lestari, N. D. S., Juniati, D., \& Suwarsono, S. (2018). Gender differences in prospective teachers' mathematical literacy: Problem solving of occupational context on shipping company. Journal of Physics: Conference Series, 1008(1). https://doi.org/10.1088/17426596/1008/1/012074

Lim, W., \& Guerra, P. (2013). Using a Pedagogical Content Knowledge Assessment to Inform a Middle Grades Mathematics Teacher Preparation Program. Georgia Educational Researcher, 10(2). https://doi.org/10.20429/ger.2013.1 00201

Ma’Rufi, Budayasa, I. K., \& Juniati, D. (2017). Pedagogical content knowledge: Knowledge of pedagogy novice teachers in mathematics learning on limit algebraic function. AIP Conference Proceedings, 1813. https://doi.org/10.1063/1.4975975

Ma'Rufi, Budayasa, I. K., \& Juniati, D. (2018). Pedagogical Content Knowledge: Teacher's Knowledge of Students in Learning Mathematics on Limit of Function Subject. Journal of Physics: Conference Series, 954(1). https://doi.org/10.1088/17426596/954/1/012002

Ma'Rufi, Ikram, M., \& Ilyas, M. (2020). Exploration of Pre-Service Teachers' Pedagogical Content Knowledge in Mathematics Learning in Senior High School Based on Gender and Academic Skills. Journal for the Education of Gifted Young Scientists, 8(4), 1361-1371. https://doi.org/10.17478/jegys.780 399 
DOI: https://doi.org/10.24127/ajpm.v9i4.3171

Maryono. (2015). Analisis Pedagogical Content Knowledge ( Pck ) Guru Matematika Dan Praktik Pembelajarannya. Jurnal Pendidikan Dan Pembelajaran Matematika (JP2M), 1(1), 58-71.

Muhtarom, Juniati, D., \& Siswono, T. Y. E. (2019). Examining prospective teachers' belief and pedagogical content knowledge towards teaching practice in mathematics class: A case study. Journal on Mathematics Education, 10(2), 185-202. https://doi.org/10.22342/jme.10.2.7 326.185-202

Nurhasanah, F., Kusumah, Y. S., \& Sabandar, J. (2017). Concept of Triangle: Examples of Mathematical, 1(1), 53-70.

Qiao-Ping, Z., Ngai-Ying, W., \& ChiChung, L. (2013). Teacher ' s Gender-Related Beliefs about Mathematics. Journal of the Korean Society of Mathematical Education Series D: Research in
Mathematical Education, 17(3), 153-167.

Rochintaniawati, D., Widodo, A., Riandi, R., \& Herlina, L. (2018). Pedagogical Content Knowledge Depelopment of Science Prospective Teachers in Professional Practice Program. Unnes Science Education Journal, $7(2)$.

https://doi.org/10.15294/usej.v7i2. 23291

Stevenson, M. (2020). Growth of pedagogical content knowledge and 'understanding mathematics in depth': conceptions of pre-service teachers. Teacher Development, 24(2), 165-183. https://doi.org/10.1080/13664530.2 020.1730944

Subanji. (2012). Peningkatan Pedagogical Content Knowledge Guru Matematika Dan Praktiknya Dalam. Jurnal Ilmu Pendidikan, jilid 21, 71-79. 